\title{
Über ein isomeres Jodmethyl-Brucin
}

\author{
von
}

\section{Ed. Lippmann.}

\begin{abstract}
Aus dem chemischen Laboratorium des Prof. Ed. Lippmann
\end{abstract} an der $\mathrm{k} . \mathrm{k}$. Universität in Wien.

(Vorgelegt in der Sitzung am 18. Jänner 1894.)

Das Brucin unterscheidet sich vom Strychnin, dass zwei Atome Wasserstoff durch zwei Methoxylgruppen ersetzt sind, so dass für das erstere Alkaloid die Formel $\mathrm{C}_{15} \mathrm{H}_{17} \mathrm{~N}_{2} \mathrm{O}_{2}$ $-\mathrm{C}_{6} \mathrm{H}_{3}\left(\mathrm{OCH}_{3}\right)_{2}$ angenommen wird. Der Rest $\mathrm{C}_{15} \mathrm{H}_{17} \mathrm{~N}_{2} \mathrm{O}_{2}$ enthält zwei Stickstoffatome, wovon das eine einem Chinolinring, das andere vielleicht einem Indol oder Carbazolring angehört. Die Function dieser beiden Stickstoffatome ist also verschieden. Es war nun möglich, dass durch Addition von Methyljodid an Brucinjodhydrat $\mathrm{C}_{23} \mathrm{H}_{26} \mathrm{~N}_{2} \mathrm{O}_{4} \mathrm{HJ}$ ein mit dem durch Anlagerung von Jodmethyl an Brucin erhaltenen Jodid Isomeres erhalten werde.

Diese Reaction wäre vollkommen analog jener des Cinchonins, wie dieselbe von Skraup ${ }^{1}$ und mir $^{2}$ bereits mitgetheilt worden ist.

Brucinjodhydrat wird erhalten, wenn man reines Brucin es wurde das von Merck in Darmstadt bezogene Alkaloid verwendet - in Wasser suspendirt und verdünnte Jodwasserstoffsäure zusetzt, bis die Lösung noch deutlich alkalisch reagirt. Das so erhaltene Jodhydrat krystallisirt in weissen Nadeln, die abgesaugt und auf einer Thonplatte getrocknet wurden. Es wurde nun eine abgewogene Menge desselben in Weingeist

1 Berichte der Deutschen chem. Gesellschaft, Septemberheft 1893.

2 Aliadem. Anzeiger, 1893, Nr. 21. 
gelöst und diese Lösung mit der molecularen Quantität Methyljodid im Einschlussrohr am Wasserbade längere Zeit erhitzt.' Das hiebei entstehende Jodmethyl-Brucinjodhydrat ist in kaltem Alkohol sehr schwer löslich, so dass der Röhreninhalt zunächst abgesaugt wurde, wobei der grösste Theil in farblosen Krystallen erhältlich ist.

Werden dieselben mit Ammon zersetzt, so erhält man Nadeln, die in kaltem Wasser sehr schwer löslich sind. Sie wurden desshalb aus diesem Mittel wiederholt umkrystallisirt. Man erhält dann dünne Prismen, die bei $198-200^{\circ}$ durchsichtig werden und sich bei $260^{\circ}$ unter heftigem Aufbrausen und Schwärzen zersetzen.

I. $0 \cdot 2697 \mathrm{~g}$ wasserfreier Substanz, die bei $120^{\circ}$ constantes Gewicht zeigte, wurden mit einem Überschusse von Silbernitrat und verdünnter Salpetersäure zersetzt, digerirt etc. und gaben $0 \cdot 1163 \mathrm{~g}$ Jodsilber.

II. $0.3317 \mathrm{~g}$ lieferten bei $130^{\circ}$, wie oben getrocknet und behandelt, $0 \cdot 1439 \mathrm{~g}$ Jodsilber.

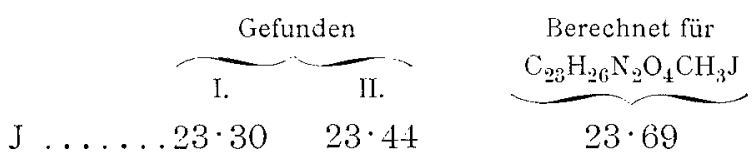

Das isomere Brucinjodmethylat, das bereits von Stahlschmidt ${ }^{2}$ und ' $\mathrm{Tafel}^{3}$ untersucht worden ist, wird sehr leicht durch Anlagerung von Jodmethyl an Brucin erhalten; es stellt glänzende Blättchen dar, die sich, ohne zu schmelzen, bei $270^{\circ}$ schwärzen und sich unter Aufbrausen bei $280^{\circ}{ }^{4}$ zersetzten.

Die ausführliche Untersuchung dieser Verbindungen, das Studium ihrer Zersetzungen, sowie die Anwendung dieser Reaction auf das verwandte Strychnin möge mir für einige Zeit vorbehalten bleiben.

1 Unter näher zu erforschenden Bedingungen bleibt, wie ich später gefunden, das Brucinjodhydrat intact.

2 J. 1859.

3 Ber., 23.

t Claus fand $290^{\circ}$, Hansen $270^{\circ}$. 